\title{
Best Possible Medication History by a Pharmacy Technician at a Tertiary Care Hospital
}

\author{
Shahileen Remtulla, Glen Brown, and Luciana Frighetto
}

\section{INTRODUCTION}

$\mathrm{A}^{\mathrm{t}}$ all interfaces of care during a hospital stay (admission, transfer, and discharge), the potential exists for inaccurate information about a patient's drug therapy to be used for various purposes. If inaccurate information is used in establishing or modifying therapy, adverse drug events may occur. Such adverse events may span the range of drug-related problems, from inappropriate initiation or discontinuation to inappropriate route or dose.

Medication reconciliation upon admission to hospital has been recognized as an important process in preventing adverse drug events at one interface of care. ${ }^{1}$ Conceptually, medication reconciliation on admission involves compiling an accurate list of the patient's medications before admission (the best possible medication history $[\mathrm{BPMH}]$ ) and ensuring that any subsequent therapy does not result in new drug-related problems. For optimal therapeutic transition, the BPMH would be obtained before any admission orders were written. However, many factors, such as cognitive impairment or a need to stabilize the patient's condition, can prevent completion of the BPMH before in-hospital initiation of therapy. An alternative approach would be to compare the BPMH with therapy prescribed in hospital at some point after admission. This would allow prompt and efficient initiation of drug therapy but would also ensure subsequent review to identify and resolve any discrepancies. Such a comparison between the BPMH and admission orders ensures continuation of all appropriate medications while the patient is in hospital.

Because medication reconciliation will be a requirement for hospital accreditation by $2010,{ }^{1}$ it was necessary to devise a strategy for implementing this process at the authors' hospital. Until now, physicians and nurses have reviewed each patient's history at the time of admission, although neither discipline has medication use as the primary focus of these investigations.
Pharmacists have extensive knowledge about medications, as well as the patient-interviewing skills required for high-quality assessment of patients' drug therapy needs during transitions of care. However, pharmacists' expertise would be better used in assessing the appropriateness of therapy rather than performing the technical task of compiling a BPMH. Because of resource constraints leading to inadequate attention or time on the part of physicians, nurses, and pharmacists, an alternative method of obtaining the BPMH was required. Although some institutions have assisted the admitting physicians or nurses by developing a standardized documentation form for use during the admission process, such forms have not been demonstrated to improve the rate of identified discrepancies upon admission. ${ }^{2}$ The use of pharmacy students for medication reconciliation has been reported, but the need to ensure a continuous supply of students and to provide training for new students limits the applicability of this method for most institutions. ${ }^{3}$

Several centres have studied the participation of pharmacy technicians in the medication reconciliation process. ${ }^{4-7}$ In these studies and others, the technicians were able to complete the BPMH with a 95\% accuracy rate (B. Tugwood, Trillium Health Centre, personal communication by e-mail, January 29, 2008), and their involvement in medication reconciliation reduced the time spent by physicians, nurses, and pharmacists at the time of admission (L. Saulnier, South-East Regional Health Authority, personal communication by e-mail, August 14, 2007). When working in conjunction with a pharmacist, technicians can obtain the information necessary for timely identification and reconciliation of discrepancies, thus helping to prevent the occurrence of adverse drug events.

Pharmacy technicians appear to be suitable candidates for completing medication histories. They are familiar with the dosage forms, strengths, and usual dosing schedules of a wide range of medications. In addition, they have received training 
about the medications that can be obtained without a prescription, which facilitates the identification of medications not included in prescription databases, such as the BC PharmaNet. Although lacking a pharmacist's understanding of the indications, side effects, and combinations of medications, pharmacy technicians have many skills that allow identification of medications used on an outpatient basis. The study reported here was undertaken to demonstrate the feasibility of training a hospital pharmacy technician to obtain the $\mathrm{BPMH}$ and to communicate discrepancies to the pharmacist for patients who had been admitted to a tertiary care hospital.

\section{DESCRIPTION OF THE PROGRAM}

A pharmacy technician with good interpersonal and communication skills, as well as extensive experience in both community and hospital settings, was selected to undergo training in completing a BPMH. A 7-day training program involving both independent study and observation or supervised participation was developed specifically for this purpose. At the beginning of the training program, the technician read written material about the purpose and process of medication reconciliation, the potential role of the technician in medication reconciliation, and the format of a patient interview. The technician discussed the instruction material daily with a supervising pharmacist. The technician provided daily written and verbal feedback on the appropriateness of the material, the pace of teaching, the order of material presented, and the time allotted for each topic. No adjustments to the training schedule were required on the basis of this feedback. Once the didactic instruction had been completed, the technician was given the opportunity to directly observe a pharmacist obtaining medication histories, to conduct patient interviews under supervision, and then, once the technician had demonstrated acceptable proficiency, to complete the interviews independently. As the technician began to work independently, a daily routine was established to maximize the number of patients interviewed. During the course of the study, some interviews conducted by the technician were observed by a pharmacist on an unscheduled basis for quality assurance, to verify adequacy of data collection, and to identify medication discrepancies.

The technician performed patient interviews from Monday to Friday for patients admitted to the surgical and medical wards (175 beds) of the 440-bed tertiary care hospital. Each morning, all patients who had been admitted in the previous 24 hours and for whom medications had been prescribed were identified by reviewing the hospital's admission data, which were obtained through the Pharmacy's database. For each patient identified, the technician attempted to complete a BPMH within $24 \mathrm{~h}$ of admission. Before interviewing any patient, the technician printed the person's inpatient drug profile and the provincial prescription database (PharmaNet) profile. The technician used a form (developed for the purposes of this study) to collect patient information, including pertinent drug information, allergy status, and body weight (Appendix 1). The information collected during the technician's interview with the patient (the BMPH) was compared with the current inpatient drug profile to identify any medications that had been taken before admission that were absent or prescribed at different doses in hospital. Any such discrepancies were communicated to a pharmacist, who determined the need to alter the current drug regimen or contacted the prescriber for advice about drug-related problems that could not be resolved directly. The pharmacist used a previously published classification system ${ }^{1}$ to determine the contributors to any identified discrepancies (Table 1). The BPMH documentation form used was signed by both the technician and the pharmacist, regardless of the presence or absence of discrepancies, and was placed in the patient's health care record.

\section{RESULTS}

The study ran from January 14 to March 6, 2008, inclusive (39 working days). During the study period, the pharmacy technician approached a total of 415 patients, for an average of 11 attempts per day. A total of 89 interviews (21\%) could not be completed for various reasons: language barrier (28 [31\% of those not completed]), problems with alertness or cooperation (56 [63\%]), and other reasons (7 [8\%]); the resulting number of completed interviews was therefore 326, or an average of 8 completed interviews per day. Some patients had more than one barrier that prevented the interview from occurring.

The average time required for each interview was $12 \mathrm{~min}$ (range 2-48 $\mathrm{min}$ ). The recorded interview time included the technician's initial review of the patient's health record, but not the process of identifying patients each morning or the preparation of BMPH paperwork. The documented time also did not include the time spent by the pharmacist to assess the $\mathrm{BMPH}$ and resolve any discrepancies. For the 326 completed interviews, the total number of medications before admission was 1345 (average 4 medications per patient). The technician identified a total of 775 discrepancies (Table 1). The total number of unintentional discrepancies was 75 , representing an occurrence rate of about 1 for every 4 patients.

\section{DISCUSSION}

Obtaining accurate and comprehensive information about a patient's medication therapy before admission is an essential aspect of preventing drug-related problems during a hospital stay. ${ }^{1}$ This study demonstrated the feasibility of training a 
Table 1. Medication Discrepancies Identified During the Study Period

\begin{tabular}{llc} 
Discrepancy Type & \multicolumn{1}{c}{ Definition } & $\begin{array}{c}\text { No. of Discrepancies } \\
\text { Identified }\end{array}$ \\
\hline Type 0 & No discrepancy & 570 \\
\hline Type 1 & $\begin{array}{l}\text { Documented intentional discrepancy: physician made an } \\
\text { intentional choice to add, change, or discontinue a } \\
\text { medication, and this choice was clearly documented }\end{array}$ & 339 \\
\hline Type 2 & $\begin{array}{l}\text { Undocumented intentional discrepancy: physician } \\
\text { made an intentional choice to add, change, } \\
\text { or discontinue a medication, but this choice was not } \\
\text { clearly documented }\end{array}$ \\
\hline Type 3 & $\begin{array}{l}\text { Unintentional discrepancy: physician unintentionally } \\
\text { changed, added, or omitted a medication that the } \\
\text { patient was taking before admission }\end{array}$ \\
\hline Unclassified & Pharmacist did not specify the classification on the form & \\
\hline
\end{tabular}

pharmacy technician to complete medication histories for medical and surgical patients in a tertiary care hospital. During the patient interviews, numerous medication discrepancies were identified, which were referred to the pharmacist to resolve as appropriate.

As expected, most of the discrepancies identified were intentional (Table 1 , types 1 and 2). About $10 \%$ of the discrepancies were unintentional (Table 1, type 3), and this type of discrepancy has the greatest potential for subsequent adverse drug events. ${ }^{8}$ Unclassified discrepancies involved patients who were discharged before the pharmacist could resolve the discrepancies with the physician (i.e., incomplete resolution of discrepancies) and cases in which the pharmacist was unable to clearly assign a type because of inexperience at the beginning of the study period.

One of the limitations of this study was a lack of generalizability, given that the study involved training a single technician at a single institution. The technician's familiarity with the Pharmacy's database allowed her to move through the training process quickly. The technician relied heavily on her knowledge of the physical characteristics (e.g., shape, colour) of the medications in gathering information from patients. A longer training period might be required, depending on the skills and experience of any technicians recruited for this role in the future. The training process should be repeated with technicians of various backgrounds to obtain a more accurate estimate of the training time required.

The process for identifying suitable patients for the medication interviews was identified as an area requiring improvement. A substantial portion of the technician's time was spent on preparatory work, rather than conducting patient interviews. Having the ability to determine which patients would not be able to provide the information required for the BPMH because of a language barrier, decreased alertness, or short hospital stay would eliminate unnecessary work and permit completion of more patient interviews each day.
Completing the BPMH in preadmission surgical clinics and using the hospital's translation services might improve this process.

Feedback from the pharmacists who participated in the study included a suggestion to develop a system for classifying the severity of the discrepancies identified. For example, a type 3 discrepancy involving a high-risk medication (e.g., warfarin or digoxin) should be brought to the pharmacist's attention immediately, whereas a type 3 discrepancy for a natural supplement or herbal product usually would not require prompt action. Such prioritization would help the pharmacists to manage their workload more efficiently. Also, for purposes of scheduling and resource allocation, it would be beneficial to measure the amount of time required for pharmacists to categorize the discrepancies and complete the form.

On the basis of the results of and lessons learned from this study, an expansion of current pharmacy technician activities appears feasible. As more technicians are trained to obtain medication histories, this service could be offered to a wider patient population.

Overall, the results of this study support the concept of pharmacy technicians obtaining the BPMH. Incorporating technicians into the medication reconciliation process could help to make this service available to more hospital inpatients.

\section{References}

1. Getting started kit: medication reconciliation prevention of adverse drug events how-to guide. Edmonton (AB): Safer Healthcare Now! Campaign; 2007 May [cited 2007 Aug 15]. Available from: http://www.saferhealthcarenow.ca/Default.aspx?folderId=82\&contentId=124

2. Jacko Namespetra M. Admission to discharge: development of a seamless discharge prescription form. Can J Hosp Pharm 2008;61(4):267-272.

3. Lubowski TJ, Cronin LM, Pavelka RW, Briscoe-Dwyer LA, Briceland LL, Hamilton RA. Effectiveness of a medication reconciliation project conducted by PharmD students. Am J Pharm Educ 2007;71(5):Article 94.

4. Bayley KB, Savitz LA, Maddalone T, Stoner SSE, Hung JS, Wells R. Evaluation of patient care interventions and recommendations by a transitional care pharmacist. Ther Clin Risk Manag 2007;3(4):695-703.

5. Michels RD, Meisel SB. Program using pharmacy technicians to obtain medication histories. Am J Health Syst Pharm 2003;60(19):1982-1986. 
6. Nester TM, Hale LS. Effectiveness of a pharmacist-acquired medication history in promoting patient safety. Am J Health Syst Pharm 2002; 59(22):2221-2225.

7. Tizard J. Taking drug histories — an audit of technician accuracy. Hosp Pharm 2007;14(10):351-352.

8. Cornish PL, Knowles SR, Marcheso R, Tam V, Shadowitz S, Juurlink DN, et al. Unintended medication discrepancies at the time of hospital admission. Arch Intern Med 2005;165(4):424-429.

Shahileen Remtulla, BSC, BSc(Pharm), ACPR, is with the Pharmacy, Providence Health Care, Vancouver, British Columbia.

Glen Brown, BSC(Pharm), PharmD, FCSHP, BCPS, is with the Pharmacy, Providence Health Care, Vancouver, British Columbia.
Luciana Frighetto, BSC(Pharm), MBA, FCSHP, is Operations Director for the Department of Pharmacy, Providence Health Care, Vancouver, British Columbia.

\section{Address correspondence to:}

Shahileen Remtulla

Pharmacy

St Paul's Hospital

1081 Burrard Street

Vancouver BC V6Z 1Y6

e-mail: Shahileen.remtulla@vch.ca

\section{Acknowledgements}

We would like to thank Jennifer Hoffman, Pharmacy Technician, for her understanding and effort in making this project a success.

Appendix 1. Form used by technician for completing the best possible medication history. (c)2008 Providence Health Care. Reproduced with permission.

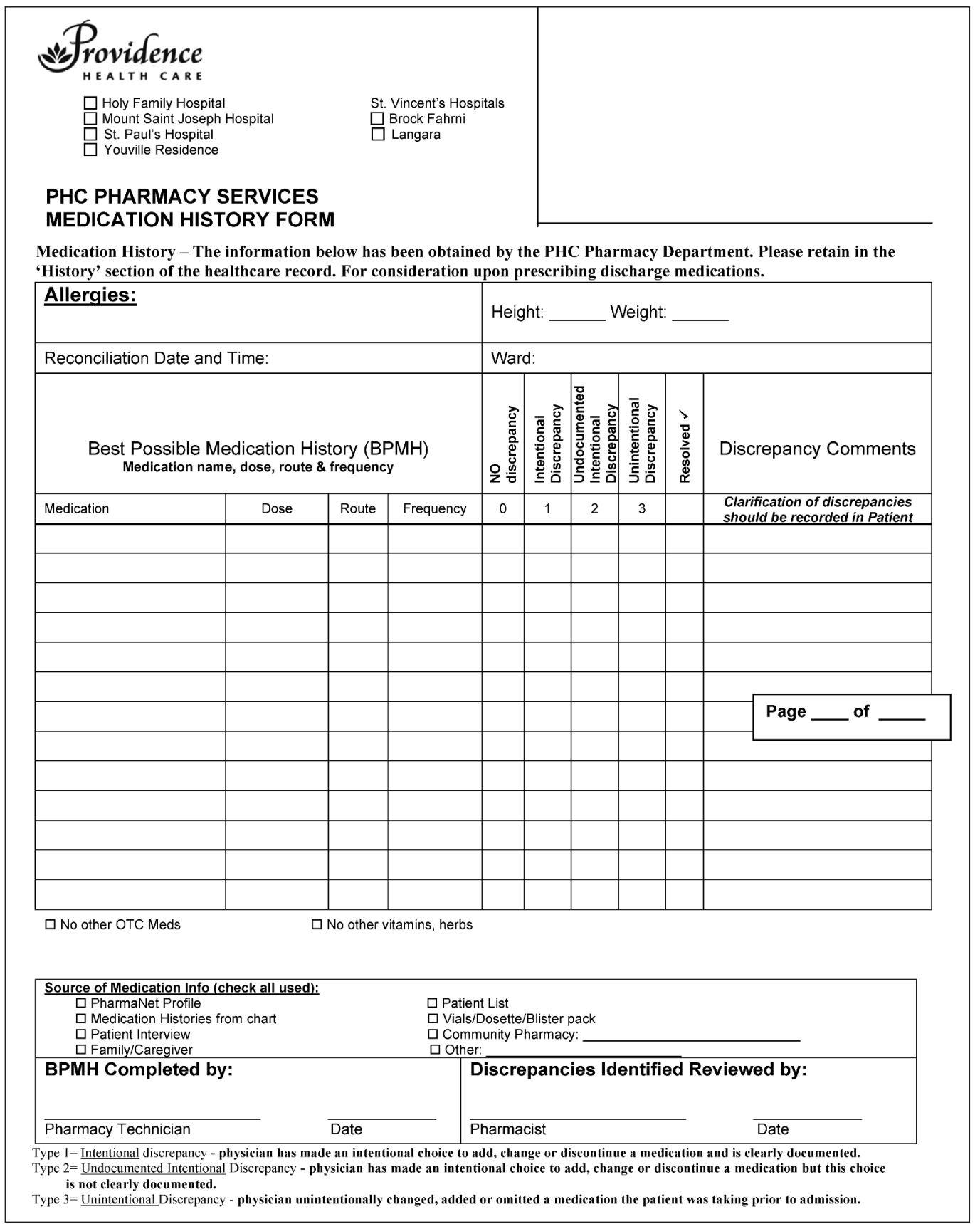

